\title{
Evaluation of Nano-Patterning Performance of Water-Soluble Material for Photoresist Using Sugar Chain
}

\author{
Toru Amano ${ }^{1,2^{*}}$, Daiki Hirata ${ }^{1}$, Yumi Hasegawa ${ }^{1}$, and Satoshi Takei ${ }^{1}$ \\ ${ }^{1}$ Department of Mechanical Systems Engineering, Toyama Prefectural University, \\ Imizu, Toyama 939-0398, Japan \\ ${ }^{2}$ Gunei Chemical Industry, Takasaki, Gunma 370-0032, Japan \\ *t-amano@gunei-chemical.co.jp
}

\begin{abstract}
Hydroxyl groups of dextrin, which is a base polymer, were modified with photosensitive groups to the extent that water solubility could be maintained, and water-soluble plantderived photosensitive materials were created. This material can be applied to a silicon wafer using spin coating, exposed by a mask contact exposure system (LTCET-500: Litho Tech Japan), and then developed with water to enable fine processing, which is derived from plants for photolithography. It has been demonstrated that adaptation to water-soluble nanopatterning materials is possible. Since the base polymer is derived from plants and does not use organic solvents or highly toxic strong alkaline developers, it is useful as a low environmental load patterning material.
\end{abstract}

Keywords: Nano-patterning, Photoresist, Sugar chain, Water-soluble material

\section{Introduction}

With the increase in integration, size, reliability, and signal speed of electronic devices, photoresist materials used in semiconductor manufacturing are indispensable materials, and miniaturization is progressing. Behind the evolution of electronic equipment, many resins, solvents, and alkali developing solutions used in semiconductor manufacturing are currently being treated as a large amount of waste, which is regarded as a problem.

Conventional photoresist materials are synthesized from fossil raw materials such as acrylic resin and phenol resin, applied with an organic solvent, and developed with a strong alkaline developer or organic solvent, so it is difficult to reduce a large amount of waste.

In recent years, much attention has been paid to water-soluble photoresist materials that can be coated with water and developed with water.

The main materials are only a water-soluble resin and water, and are useful as a low environmental load patterning material that does not use an organic solvent or a highly toxic strong alkaline developer.

Many studies have been made on water-soluble resins such as polyvinyl alcohol and polyacrylamide.
However, since they are manufactured from fossil raw materials, they cannot be said to have a small environmental load [1-8].

As a water-soluble resist material having a low environmental load, a material using a saccharide has been proposed, but since the coating is performed using an organic solvent, it cannot be said to be sufficient as a low environmental load [9].

Therefore, by creating a water-soluble photoresist material that can be coated with water and developed with water, using a plant-derived and water-soluble saccharide (dextrin) as a raw material, it has a lower environmental impact than conventional water-soluble nano-patterning materials. We propose a new water-soluble nanopatterning material for plant-based photoresist.

In this paper, in order to confirm the effectiveness of a plant-based water-soluble nano-patterning material for photo-resist using sugar chains, the hydroxyl group of dextrin as a base polymer is modified with a photosensitive group to the extent that water solubility can be maintained. We report on coating properties, exposure sensitivity, and patterning properties. 


\section{Experimental, results, and discussion}

\subsection{Creating a base polymer}

The sugar chains used in this study were made from dextrin (product name: NSD500) manufactured by San-ei Sucrochemical. Also, from the knowledge of conventional photoresist materials, it is known that low molecular weight compounds cause deterioration of curability after exposure, and that if the molecular weight distribution is too wide, the sensitivity of exposure will deteriorate, so that good patterning is achieved. In order to form dextrin, it is necessary to remove low molecular weight substances contained in dextrin.

As a removing method, dextrin was dissolved in water, and then alcohol such as methanol and ethanol was added to precipitate only the polymer portion in the dextrin. The removal amount of low molecular weight can be arbitrarily controlled by the mixing ratio of water and the solvent, and the more water, the more low molecular weight can be removed.

Figure 1 and Table 1 show the results of Gel Permeation Chromatography measurement (GPC) performed to confirm the molecular weight distribution of the base polymer obtained by removing low molecular weight compounds.

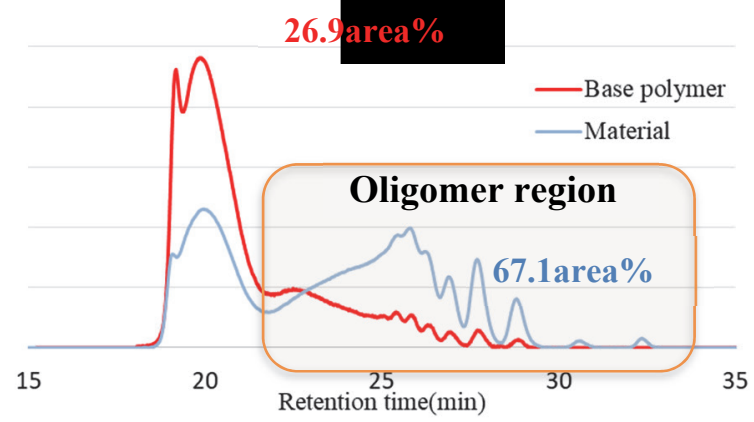

Fig. 1. Comparison of molecular weight distribution of raw material and base polymer.

Table 1. GPC measurement result of raw material and base polymer.

\begin{tabular}{|l|c|c|c|}
\hline & $M \mathrm{n}$ & $M \mathrm{w}$ & $\begin{array}{c}\text { Oligomer } \\
\text { amount (area\%) }\end{array}$ \\
\hline $\begin{array}{l}\text { Base } \\
\text { polymer }\end{array}$ & 7160 & 32600 & 26.9 \\
\hline Material & 2450 & 11400 & 67.1 \\
\hline
\end{tabular}

The number average molecular weight $(M \mathrm{n})$ of the dextrin used as a raw material was 2450 , the weight average molecular weight $(\mathrm{Mw})$ was 11400 , and the content of the oligomer region was 67.1 area $\%$, whereas dextrin from which low molecular weight had been removed had $M n$ value of 7160 and $M \mathrm{w}$ value of 32600 , and the content of the oligomer region was 26.9 area\%. The oligomer region is small, the molecular weight distribution is narrow, and it can be seen that it is good as a base polymer.

\subsection{Addition of photosensitive group}

The photosensitive group was modified by $22 \%$ with respect to all the hydroxyl groups in the obtained base polymer to obtain a plant-derived water-soluble nanopatterning material for photoresist (Fig. 2).

Modification to the photosensitive group was confirmed by ${ }^{13} \mathrm{C}$-NMR and FT-IR.
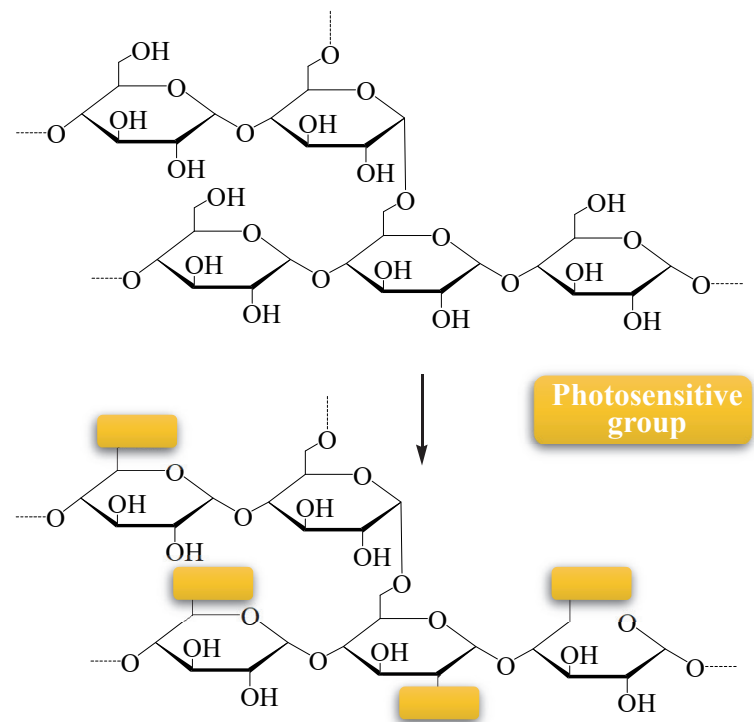

Fig. 2. Modification of hydroxyl group of base polymer to photosensitive group.

2.3. Evaluation of film thickness uniformity for rotation speed during spin coating

The prepared plant-derived water-soluble nanopatterning material for photoresist was applied to a silicon wafer by spin coating, and the film thickness uniformity was confirmed.

First, $5 \mathrm{~mL}$ of ultrapure water was spin-coated at $2000 \mathrm{rpm}$ for 30 seconds using a spin coater (MSA100: MIKASA) in order to improve coatability on a silicon wafer. Next, $1 \mathrm{~mL}$ of plant-derived watersoluble nano-patterning material for photoresist is spin-coated with a spin coater at 1000, 2000, and $3000 \mathrm{rpm}$ for 30 seconds, and baked at $120{ }^{\circ} \mathrm{C}$ for 60 seconds using a hot plate to remove water by volatilization. Was evaluated using a non-contact 
type film thickness measuring system (F20-UV: Filmetrics) (Fig. 3).

As a result, it was found that a flat film of about $\pm 10 \mathrm{~nm}$ was formed at a rotation speed of $2000 \mathrm{rpm}$ or more, and it was confirmed that the film thickness uniformity was good (Fig. 4).

It is considered that the fluctuation of the film thickness is caused by the wettability to the silicon wafer due to the water coating.

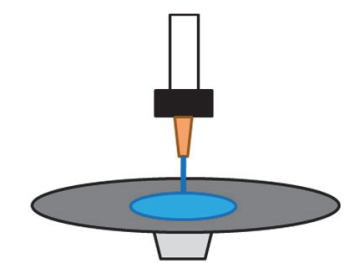

(1) Ultrapure water Drop

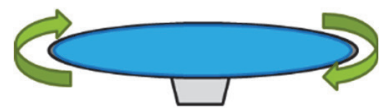

(2) Spin coat

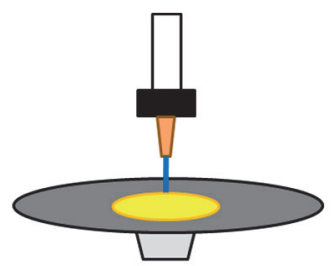

(3) Photoresist solution Drop

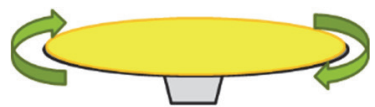

(4) Spin coat

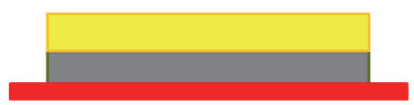

(5) Bake $120^{\circ} \mathrm{C} 60 \mathrm{~s}$

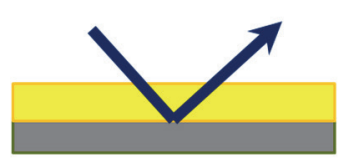

(6) Thickness measurement

Fig. 3. Spin coating process of water-soluble nanopatterning material.

2.4. Evaluation of film thickness uniformity for solid concentration

When the solid concentration of the plant-derived water-soluble nano-patterning material for photoresist was adjusted to $12.5,20.0$, and $25.0 \mathrm{wt} \%$, it was confirmed how much influence was exerted on the film thickness uniformity during spin coating.

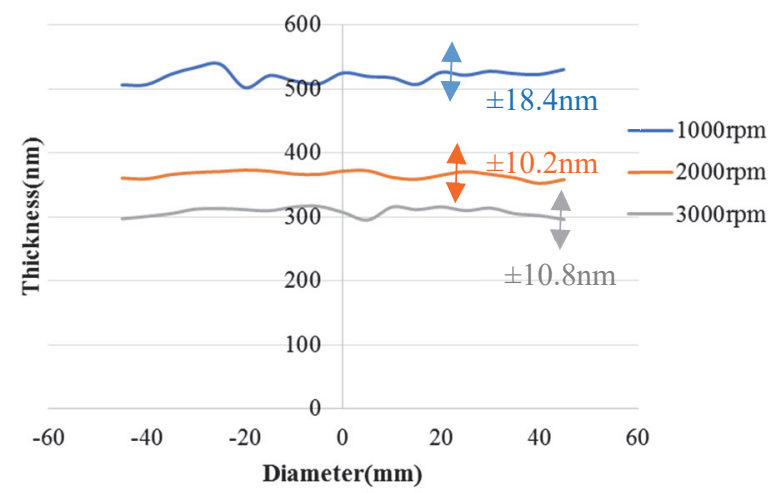

Fig. 4. Measurement results of film thickness uniformity at rotation speed during spin coating.

The rotation speed during spin coating was 2000 rpm.

As a result, it was confirmed that when the solid content concentration was high, the solution viscosity tended to increase and the uniformity of the film thickness tended to be impaired. Also, when the solid content concentration was $12.5 \mathrm{wt} \%$, it was found that a relatively flat film of about $\pm 16.3 \mathrm{~nm}$ was formed, and it was confirmed that the film thickness uniformity was good (Fig. 5).

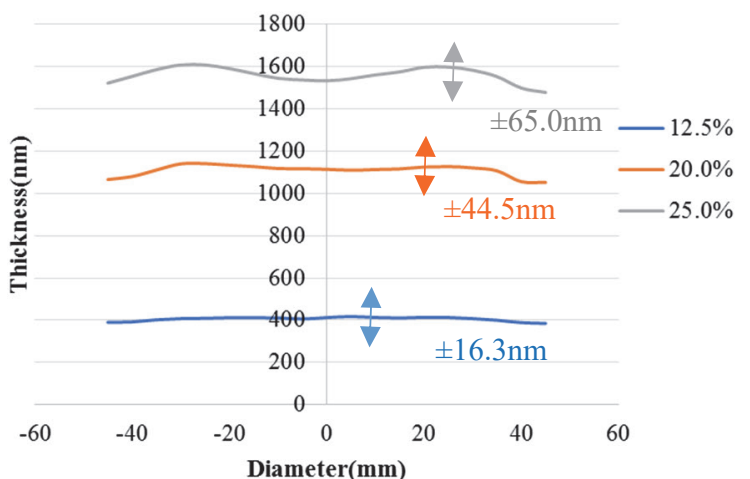

Fig. 5. Measurement results of film thickness uniformity at solid content concentration during spin coating.

2.5. Evaluation of residual film ratio for exposure and development temperature

In order to confirm the exposure sensitivity of the plant-derived water-soluble nanopatterning material for photoresist, the residual film ratio was measured at the exposure amount and the development temperature.

A plant-derived water-soluble nano-patterning material for photoresist was spin-coated at 2000 $\mathrm{rpm}$ for 30 seconds using a spin coater, and baked at $120{ }^{\circ} \mathrm{C}$ for 60 seconds to volatilize and remove water.

Next, the exposure amount was changed to 50 , 
$100,300,600$, and $1200 \mathrm{~mJ} / \mathrm{cm}^{2}$, and after measuring the film thickness, the residual film ratio when the developing temperature was 40 and $70{ }^{\circ} \mathrm{C}$ was confirmed (Fig. 6).

As a result, it was confirmed that a residual film ratio of $70 \%$ or more could be secured at an exposure amount of $50 \mathrm{~mJ} / \mathrm{cm}^{2}$.

Further, the remaining film ratio is about $90 \%$ at an exposure dose of $300 \mathrm{~mJ} / \mathrm{cm}^{2}$, and it can be said that the material exhibits relatively good exposure sensitivity (Fig. 7).

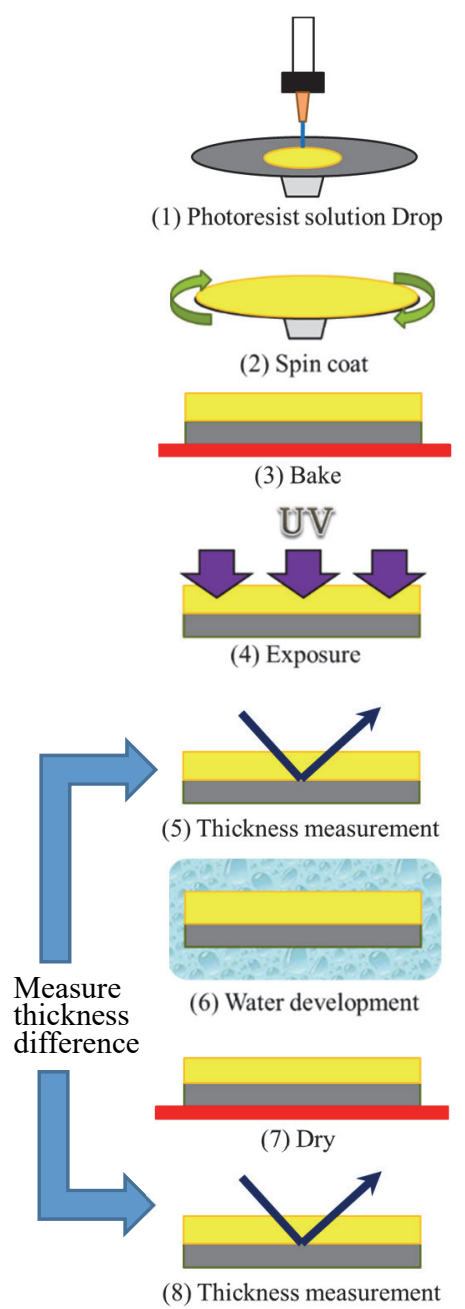

Fig. 6. Residual film measurement process after exposure and development of water-soluble nano-patterned material.

\subsection{Effect of development time}

The residual film ratio was evaluated based on the development time when the exposure amount to irradiate the plant-derived water-soluble nanopatterning material for photoresist was fixed.

A plant-derived water-soluble nanopatterning material for photoresist was spin-coated at 2000 rpm for 30 seconds using a spin coater, and baked at $120{ }^{\circ} \mathrm{C}$ for 60 seconds to volatilize and remove water.

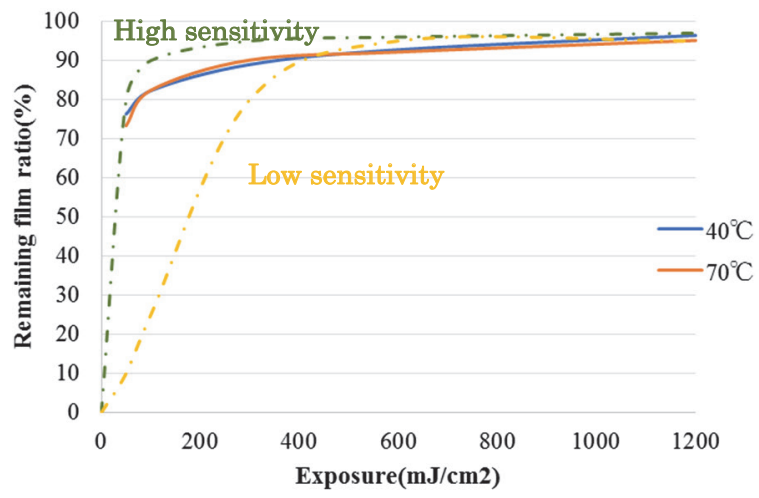

Fig. 7. Measurement results of residual film after exposure and development.

Next, the exposure was fixed at $50 \mathrm{~mJ} / \mathrm{cm}^{2}$, exposure was performed, and after measuring the film thickness, the developing temperature was set to $40^{\circ} \mathrm{C}$, and the developing time was set to 30,60 , $90,120,150,180,600,1200,2400 \mathrm{~s}$, and the remaining the film ratio was confirmed.

As a result, no difference in the remaining film depending on the development time could be confirmed (Fig. 8).

From this, it can be seen that the crosslinking reaction has sufficiently proceeded at an exposure dose of $50 \mathrm{~mJ} / \mathrm{cm}^{2}$.

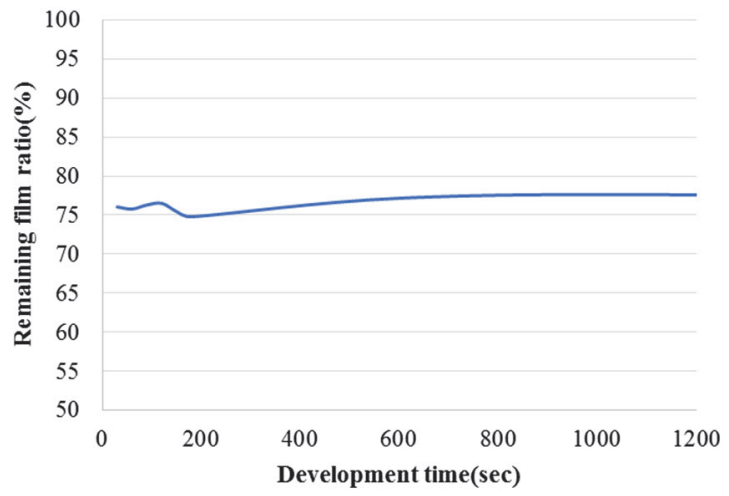

Fig. 8. Relationship between development time and residual film ratio when exposure is fixed.

\subsection{Fine processing evaluation}

We evaluated whether the plant-based watersoluble nano-patterning material for photo-resist can be finely processed.

First, $5 \mathrm{~mL}$ of ultrapure water was spin-coated at $2000 \mathrm{rpm}$ for 30 seconds using a spin coater (MS- 
A100: MIKASA) in order to improve coatability on a silicon wafer as in the previous section.

Next, $1 \mathrm{~mL}$ of a plant-derived water-soluble nano-patterning material for photoresist was spincoated with a spin coater at $2000 \mathrm{rpm}$ for 30 seconds, and baked at $120^{\circ} \mathrm{C}$ for 60 seconds using a hot plate to volatilize and remove the solvent.

Then, using a mask contact exposure apparatus (LTCET-500: Litho Tech Japan), the resist was exposed to $600 \mathrm{~mJ} / \mathrm{cm}^{2}$, and then the silicon wafer was immersed in ultrapure water at room temperature for 90 seconds and developed.

Next, the surface of the resist was air blown and dried at $120^{\circ} \mathrm{C}$ for 30 seconds using a hot plate to remove the developing solution, and fine processing was performed on the silicon wafer (Fig. 9).

The surface of the obtained silicon wafer was observed with a confocal laser microscope OPTELICS H1200 (Lasertec) (Fig. 10).

As a result, it was confirmed that microfabrication of at least about $3 \mathrm{~nm}$ was possible.

\section{Conclusion}

We investigated the effectiveness of plant-based water-soluble nano-patterning materials for photoresist using sugar chains. By converting the hydroxyl group of the sugar chain to a photosensitive group to the extent that water solubility can be maintained, a plant-derived watersoluble nano-patterning material having photosensitivity was created. The obtained nanopatterning material has good coatability and film

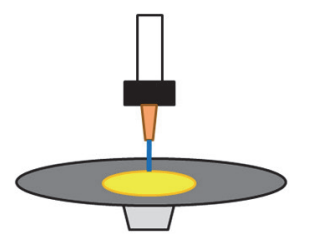

(1) Photoresist solution Drop

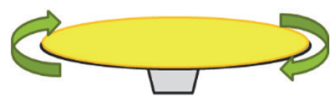

(2) Spin coat

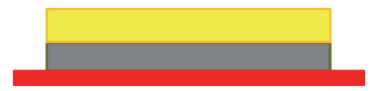

(3) Bake

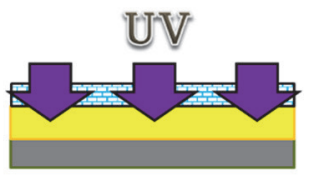

(4) Exposure $600 \mathrm{~mJ} / \mathrm{cm}^{2}$

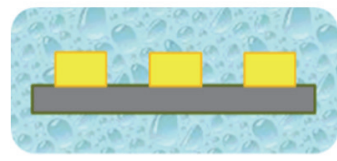

(5) Water development

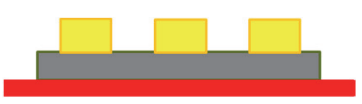

(6) Dry

Fig. 9. Microfabrication process of water-soluble nanopatterning material.
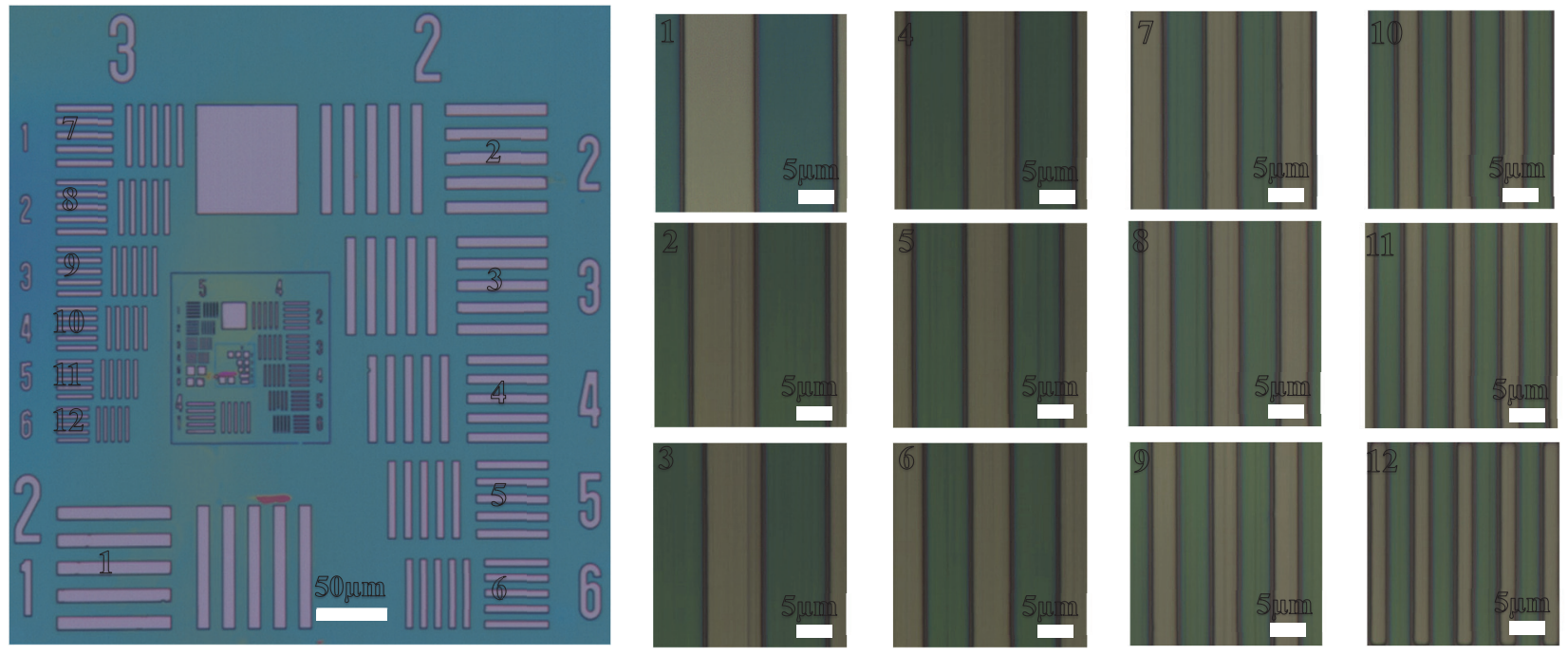

Fig. 10. Observation results of fine processing of water-soluble nano-patterning material. 
thickness uniformity. In addition, in a microfabrication test by exposure and development, it was found that microfabrication of a minimum of about $3 \mathrm{~nm}$ was possible.

This material is useful as a low environmental load patterning material that can be microfabricated.

\section{References}

1. H. Morishita, M. Ito, N. Hayashi, and S. Nonogaki, J. Photopolym. Sci. Technol., 7 (1994) 59.

2. Q. Lin, T. Steinhausler, L. Simpson, M. Wilder, D. R. Medeiros, and C. G. Willson, Chem. Mater., 9 (1997) 1725.

3. J. M. Havard, M. Yoshida, D. Pasini, N. Vladimirov, J. M. J. Frechet, D. R. Medeiros, K.
Patterson, S. Yamada, C. G. Willson, and J. D. Byers, J. Appl. Polym. Sci. Part A: Polym. Chem., 37 (1999) 1225.

4. J. M. Havard, S.-Y. Shim, and J. M. J. Frechet, Chem. Mater., 11 (1999) 719.

5. K. Kojima, M. Ito, H. Morishita, and N. Hayashi, Chem. Mater., 10 (1998) 3429.

6. J. Swei and J. B. Talbot, J. Appl. Polym. Sci., 102 (2006) 1637.

7. S.-Y. Shim and J.-M. Kim, Bull. Korean Chem. Soc., 22 (2001) 1120.

8. K. H. Chae, G. J. Sun, J. K. Kang, and T. H. Kim, J. Appl. Polym. Sci., 86 (2002) 1172.

9. Y. Y. Liao and J.-H. Liu, J. Appl. Polym. Sci., 109 (2008) 3849. 